\title{
The epigenetic effect of microRNA in BCR-ABL1-positive microvesicles during the transformation of normal hematopoietic transplants
}

\author{
NA SHEN $^{1 *}$, LIN JIANG $^{1 *},{\text { QING } \text { LI }^{2}, \text { JIEKE CUI }^{1}, \text { SHU ZHOU }^{1}, \text { FANJUN CHENG }^{1}, \text { ZHAODONG ZHONG }}^{1}$, \\ LI MENG $^{3}$, YONG YOU ${ }^{1}$, XIAOJIAN ZHU ${ }^{3}$ and PING ZOU ${ }^{1}$ \\ ${ }^{1}$ Institute of Hematology, Union Hospital, Tongji Medical College, Huazhong University of Science and Technology, \\ Wuhan, Hubei 430022; ${ }^{2}$ Department of Hematology, Wuhan No. 1 Hospital, Wuhan, Hubei 430022; \\ ${ }^{3}$ Department of Hematology, Tongji Hospital, Tongji Medical College, Huazhong University \\ of Science and Technology, Wuhan, Hubei 430030, P.R. China
}

Received March 2, 2017; Accepted August 16, 2017

DOI: 10.3892/or.2017.5966

\begin{abstract}
Epigenetics have been demonstrated to play a pivotal role in the progression of multiple cancers. Our previous study has demonstrated that microvesicles (MVs) derived from K562 cells could malignantly transform normal hematopoietic cells. The aim of this section was to elucidate the epigenetic effects of RNA in K562-MVs. We altered some epigenetic RNAs (miR-106a-5p, miR-106b-5p and lincPOU3F3) in K562-MVs and followed the process of transformation. Global DNA methylation and DNA methyltransferase (DNMT) levels were observed respectively. Our findings revealed that increased $\mathrm{miR}-106 \mathrm{a} / \mathrm{b}$ in K562-MVs accelerated the transformation process $(8.33 \pm 0.94$ vs. $13.29 \pm 1.28$ days; $\mathrm{P}<0.01)$ whereas decreased lincPOU3F3 delayed the transformation $(17.83 \pm 0.29$ days; $\mathrm{P}<0.05)$. The targets of miR-106a/b
\end{abstract}

Correspondence to: Dr Zhaodong Zhong, Institute of Hematology, Union Hospital, Tongji Medical College, Huazhong University of Science and Technology, 1277 Jiefang Road, Wuhan, Hubei 430022, P.R. China

E-mail: zhongzhaodong@medmail.com.cn

Dr Li Meng, Department of Hematology, Tongji Hospital, Tongji Medical College, Huazhong University of Science and Technology, 1095 Jiefang Road, Wuhan, Hubei 430030, P.R. China

E-mail: limeng@tjmu.edu.cn

*Contributed equally

Abbreviations: MVs, microvesicles; DNMT, DNA methyltransferase; CML, chronic myeloid leukemia; MNCs, mononuclear cells; GDM, global DNA methylation; FBS, fetal bovine serum; MSP, methylation-specific PCR; NC, negative control; DCL, donor cell leukemia; $\mathrm{BC}$, blast crisis; $\mathrm{CP}$, chronic phase; TSGs, tumor suppressor genes; RISC, RNA-induced silencing complex

Key words: epigenetics, microvesicles, microRNA, lincRNA, malignant transformation and lincPOU3F3 in the recipient cells were DNMT3a and DNMT3b. We found that lincPOU3F3 directly increased the DNMT3a/b while miR-106a/b only in part by targeting RB. However, global DNA methylation and special gene methylation was altered due to the concurrent regulation of DNMT3a and DNMT3b. Consequently, we demonstrated that tumor-derived MVs represent a notable intercellular epigenetic communication between cancer cells and recipient cells.

\section{Introduction}

Microvesicles (MVs) are extracellular vesicles released by most cells that act as mediators of intercellular communication (1). As a package of extracellular multi-molecular messages, MVs carry the proteins, lipids and nucleic acids of their parental cells, providing a potential source of biomarkers in the surveillance of disease progression and/or relapse (2). Our previous study demonstrated that MVs derived from K562 chronic myeloid leukemia (CML) cells could transform mononuclear cells (MNCs) from normal hematopoietic transplants to acute leukemia-like cancer cells, which provided multiple implications for CML transformation. During transformation, an increase in global DNA methylation (GDM) in MNCs that peaked on day 3 as compared to the control, accompanied by DNA methyltransferase (DNMT)3a and DNMT3b mRNA and protein were consistently increased (3). DNA methylation is one of the most frequent forms of epigenetic modification $(4,5)$. It is widely accepted that epigenetic and genetic alterations collaborate in the development and maintenance of cancer. Recently, epigenetic alterations have also been recognized as a major driving force in the development of several cancers, including leukemia $(6,7)$. Although DNA hypermethylation of multiple genes (DLX4, SHP-1 and HOXs) characterizes advanced stages of CML and/or the disease when resistant to imatinib (8-10), the underlying epigenetic changes of DNA methylation in CML, particularly during transformation, are not fully implicated. In our previous transformation system, MVs lost their transforming abilities and the mRNA and protein of these methyltransferases decreased following 
RNase treatment, indicating that RNAs in MVs were responsible for the transformation (3). The aim of the present study was to build the connection between the miRNA inside the MVs and the methylation of recipient cells.

\section{Materials and methods}

Cell culture and MV isolation. The human CML blast crisis cell line K562 was purchased from the China Center for Type Culture Collection (Wuhan, China) and cultured in RPMI-1640 medium containing $10 \%$ fetal bovine serum (FBS) at $37^{\circ} \mathrm{C}$ in $5 \% \mathrm{CO}_{2}$. MVs isolation was performed using a previous protocol: cells were centrifuged at $1,000 \mathrm{x} \mathrm{g}$ for $10 \mathrm{~min}$. The supernatant was centrifuged at $5,000 \mathrm{x} \mathrm{g}$ for $20 \mathrm{~min}$ to remove cellular debris, and the remaining supernatant was centrifuged at $13,000 \mathrm{x}$ g for $60 \mathrm{~min}$ to obtain MVs. MNCs were extracted from the peripheral blood mobilization using lymphocyte separation medium (TBD Science, Tianjin, China), and cultured in RPMI-1640 medium containing $15 \%$ FBS at $37^{\circ} \mathrm{C}$ in $5 \% \mathrm{CO}_{2}$.

Transformation of MNCs from normal hematopoietic transplants by $M V s$. The retained MVs were suspended in serum-free RPMI-1640 medium (to avoid MVs derived from the FBS). To generate intact MVs for the cell-based assays and other experiments, the MV-containing RPMI-1640 medium was filtered using a Millipore Steriflip polyvinylidene difluoride filter with pore sizes of $1.2 \mu \mathrm{m}$ (to filter cells) (Millipore, Billerica, MA, USA). MVs were quantified according to their total RNA content and copies of BCR-ABL1 mRNA. The MNCs were adjusted to $4 \times 10^{6}$ cells/well in 6 -well plates, and $400 \mathrm{ng}$ of MVs (containing RNA) was added to the cells 3 times a day for 14-21 days. The morphology of the transformed cells was observed using Wright-Giemsa stain. To confirm the effect of miR-106a/b, K562 cells were transfected with miR-106a/b mimics and inhibitors: K562 cells were seeded onto 6 -well plates $\left(2 \times 10^{6}\right.$ cells/well $)$ the day before transfection. The cells were transfected with $10 \mu \mathrm{l}$ of $20 \mu \mathrm{M}$ miR-106a/b inhibitors, $5 \mu \mathrm{l}$ of $20 \mu \mathrm{M}$ miR-106a/b mimics, $10 \mu \mathrm{l}$ of $20 \mu \mathrm{M}$ inhibitor negative control and $5 \mu \mathrm{l}$ of $20 \mu \mathrm{M}$ mimic negative control using riboFECTTM CP reagent (both from RiboBio, Guangzhou, China), respectively. Real-time PCR was performed to assess the level of miR-106a/b in the cells and their MVs. The supernatant of transfected cells was collected $72 \mathrm{~h}$ after transfection to isolate MVs.

Global DNA methylation. DNA was extracted using TIANamp Genomic DNA kit (DP304; Tiangen, Beijing, China). Total DNA methylation was performed using MethylFlash Methylated DNA Quantification kit (P-1035-48; Epigentek, Farmingdale, NY, USA). All procedures were conducted in accordance with the instructions of the kits.

Real-time PCR. Total RNA was extracted using TRIzol reagent kit (Invitrogen Life Technologies, Carlsbad, CA, USA). cDNA was synthesized by reverse transcription of $500 \mathrm{ng}$ of total RNA with PrimeScript ${ }^{\mathrm{TM}}$ RT Reagent kit (Clontech Laboratories, Inc.; Takara Bio USA, Inc., Mountain View, CA, USA). Real-time PCR was performed with $5 \mu$ of SYBR Premix Ex Taq (Clontech Laboratories, Inc.; Takara Bio USA,
Inc.), $0.8 \mu \mathrm{l}$ of primers (Invitrogen, Carlsbad, CA, USA), $0.2 \mu \mathrm{l}$ of ROX reference dye, $3 \mu \mathrm{l}$ of RNase-free $\mathrm{H}_{2} \mathrm{O}$ and $1 \mu \mathrm{l}$ of cDNA as a template in a final reaction volume of $10 \mu \mathrm{l}$. The PCR cycling conditions were as follows: initial melting at $95^{\circ} \mathrm{C}$ for $30 \mathrm{sec}$, followed by 40 cycles at $95^{\circ} \mathrm{C}$ for $5 \mathrm{sec}$ and $60^{\circ} \mathrm{C}$ for $30 \mathrm{sec}$. The fluorescence intensity was assessed using the ABI StepOnePlus ${ }^{\mathrm{TM}}$ Real-Time PCR System. Analysis of the melting curve for the primers was conducted to confirm the specificity of the PCR product, and the $\mathrm{Ct}$ value for triplicate reactions was averaged. The fold changes in mRNA were calculated through relative quantification $\left(2^{-\Delta \Delta C t}\right)$.

Western blotting. Cells were washed twice with phosphatebuffered saline (PBS) and lysed in RIPA buffer [1\% Nonidet $^{\mathrm{TM}}$ P-40, $1 \mathrm{mM}$ EDTA, $50 \mathrm{mM}$ Tris (pH 7.4), 0.25\% Na-deoxycholate, $150 \mathrm{mM} \mathrm{NaCl}, 1 \mathrm{mM} \mathrm{NaF}, 1 \mathrm{mM}$ sodium orthovanadate and $1 \mathrm{mM}$ phenylmethylsulfonyl fluoride (PMSF)]. The cell lysates were centrifuged at 12,000 rpm for $15 \mathrm{~min}$ at $4^{\circ} \mathrm{C}$, and the supernatants were collected. The protein concentrations were determined using a BCA protein assay kit (Pierce Biotechnology, Inc., Rockford, IL, USA). The proteins were treated with SDS sample buffer and heated at $95^{\circ} \mathrm{C}$ for $10 \mathrm{~min}$. The protein samples $(40 \mu \mathrm{g})$ for each well were separated by sodium dodecylsulfate-polyacrylamide gel electrophoresis and transferred to nitrocellulose membranes. The membranes were blocked with $5 \%$ non-fat milk and incubated overnight with a monoclonal antibody (1:500) at $4^{\circ} \mathrm{C}$. The blots were developed using a horseradish peroxidaseconjugated rabbit anti-human secondary antibody (1:500) and a chemiluminescent detection kit (Amersham Biosciences, Piscataway, NJ, USA).

Real-time quantitative methylation-specific PCR. Genomic DNA was isolated with the TIANamp Genomic DNA kit (DP304; Tiangen) according to the manufacturer's instructions. The methylation status of p53, c-Myc and the DLX4 promoter was evaluated by methylation-specific PCR (MSP). Briefly, genomic DNA was treated with bisulfite using the EpiTect Bisulfite kit (Qiagen, Hilden, Germany). MSP primers designed to amplify the methylated-MSP and unmethylatedMSP alleles were previously described (11-13). PCR products were resolved on $4 \%$ agarose gels, stained with ethidium bromide, and visualized under ultraviolet illumination.

Statistical analysis. SPSS 10.0 was used for statistical analysis (SPSS, Inc., Chicago, IL, USA). Non-parametric and unpaired t-test comparisons were used to compare the groups; the rates between the groups were compared by the Chi-square test. Two-sided $\mathrm{P}<0.05$ was defined as being statistically significant.

\section{Results}

Relative expression of miR-106a-5p, miR-106b-5p and lincPOU3F3 in K562 and K562-MV after transfection. PCR analysis was used to identify the relative expression of miRNA and lincRNA after transfection with miRNA mimics, inhibitors, siPOU3F3 and the scrambled negative control (NC) RNA, respectively. As expected, the expression levels of $\mathrm{miR}-106 \mathrm{a} / \mathrm{b}$ were markedly increased in the K562 and K562-MVs transfected with the mimics, and reached 

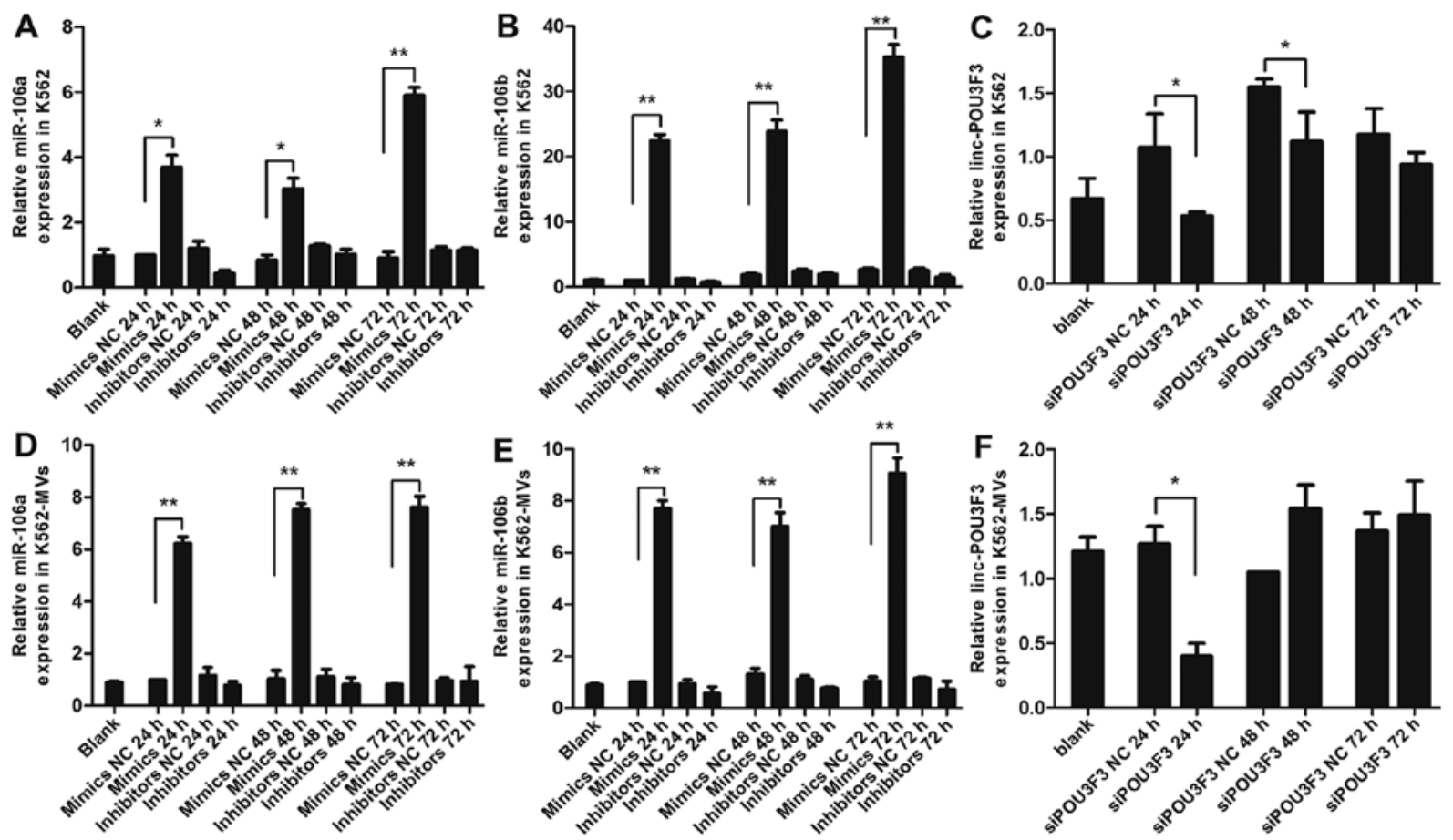

Figure 1. Relative expression of miR-106a-5p, miR-106b-5p and lincPOU3F3 in K562 and K562-MVs after transfection. (A-C) The expression levels of miR-106a-5p, miR-106b-5p and lincPOU3F3 in K562 and (D-F) K562-MVs were respectively assessed by qRT-PCR analysis at different time-points $(24,48$ and $72 \mathrm{~h})$ after transfection. The experiments were performed in triplicate, and the results were indicated as the mean $\pm \mathrm{SEM}$; $\mathrm{P}<0.05$ and ${ }^{* *} \mathrm{P}<0.01$ when comparing cells transfected with mimics or siRNA to NC groups. MVs, microvesicles.

a peak at $72 \mathrm{~h}(\mathrm{P}<0.01$ or $\mathrm{P}<0.05$; Fig. $1 \mathrm{~A}, \mathrm{~B}, \mathrm{D}$ and $\mathrm{E})$. Whereas, the expression levels of miR-106a/b were relatively decreased in cells and MVs transfected with the inhibitors. However, compared with the control, these decreases were not significant ( $\mathrm{P}>0.05$; Fig. 1A, B, D and E). The conceivable reason for this is that inhibitors suppress downstream pathways by binding miRNA, but do not affect its expression. No significant differences were observed between the mimics $\mathrm{NC}$ or the inhibitors $\mathrm{NC}$ and blank groups $(\mathrm{P}>0.05$; Fig. 1A, B, D and E). As for lincPOU3F3, the expression in the K562 and K562-MVs was the lowest at $24 \mathrm{~h}$ after transfection with siPOU3F3 ( $\mathrm{P}<0.05$; Fig. $1 \mathrm{C}$ and F). However, when detected at 48 and $72 \mathrm{~h}$, there was no statistical significance between the siNC and siPOU3F3 (both P $>0.05$; Fig. $\mathrm{C}$ and F). According to the aforementioned results, we selected K562-MVs transfected with miRNA at $72 \mathrm{~h}$ and siPOU3F3 at $24 \mathrm{~h}$ for follow-up experiments.

$M V$-delivered miR-106a-5p, miR-106b-5p and lincPOU3F3 accelerates the transformation process. To determine whether $\mathrm{MV}$-associated $\mathrm{miR}-106 \mathrm{a} / \mathrm{b}$ were functional for the transformation, we added K562-MVs at different levels of miR-106a/b (normal K562, miR-106a/b mimics and miR-106a/b inhibitors) into the recipient cells, using K562-MVs as a control. We found that a high level of miR-106a/b in K562-MVs accelerated the transformation process $(8.33 \pm 0.94$ vs. $13.29 \pm 1.28$ days; $\mathrm{P}<0.001$; Table I). Whereas, a decreased level of miR-106a/b did not stop the transformation, but resulted in a 3-day delay, leading to a transformation spanning 16 days $(16 \pm 0.82$ vs. $13.29 \pm 1.28$ days; $\mathrm{P}<0.01$; Table I). Similarly, we also found that K562-MVs with siPOU3F3 delayed the transformation span to day 17 (17.83 \pm 0.29 vs. $13.29 \pm 1.28$ days; $\mathrm{P}<0.01$; Table I).
Table I. Roles of miR-106a/b and lincPOU3F3 in the transformation process.

\begin{tabular}{lccc}
\hline Groups & $\begin{array}{c}\text { Recipient } \\
\text { cells }\end{array}$ & $\begin{array}{c}\text { No. of } \\
\text { cells }\end{array}$ & Time (days) \\
\hline $\begin{array}{l}\text { K562-MVs } \\
\text { K562-MVs } \\
\text { with increased } \\
\text { miR-106a/b }\end{array}$ & Mobilization & $4 \times 10^{6}$ & $13.29 \pm 1.28$ \\
$\begin{array}{l}\text { K562-MVs } \\
\text { with decreased } \\
\text { miR-106a/b }\end{array}$ & Mobilization & $4 \times 10^{6}$ & $16 \pm 0.82^{\mathrm{a}}$ \\
$\begin{array}{l}\text { K562-MVs } \\
\text { with siPOU3F3 }\end{array}$ & Mobilization & $4 \times 10^{6}$ & $17.83 \pm 0.29^{\mathrm{a}}$ \\
\hline
\end{tabular}

Transformation time is the first time aberrant cells were observed based on morphology. ${ }^{a} \mathrm{P}<0.01,{ }^{\text {b }} \mathrm{P}<0.001$. MVs, microvesicles.

GDM is involved in transformation. We confirmed again an increase in GDM in K562-MV-treated cells that peaked on day 3. Using K562-MV-treated cells as a control, the GDM of the K562-MV group with increased $\mathrm{miR}-106 \mathrm{a} / \mathrm{b}$ expression was increased, particularly at days 3 and $14(\mathrm{P}<0.05)$; in contrast, decreased miR-106a/b expression in K562-MVs decreased the GDM of recipient cells, particularly at days 3 and $14(\mathrm{P}<0.05)$, and the peak time was delayed to day 7 . The difference of GDM between the K562-MV groups with increased/decreased miRNA and the control was not significant at day 7 ( $\mathrm{P}>0.05$; Fig. 2A). In comparison with 

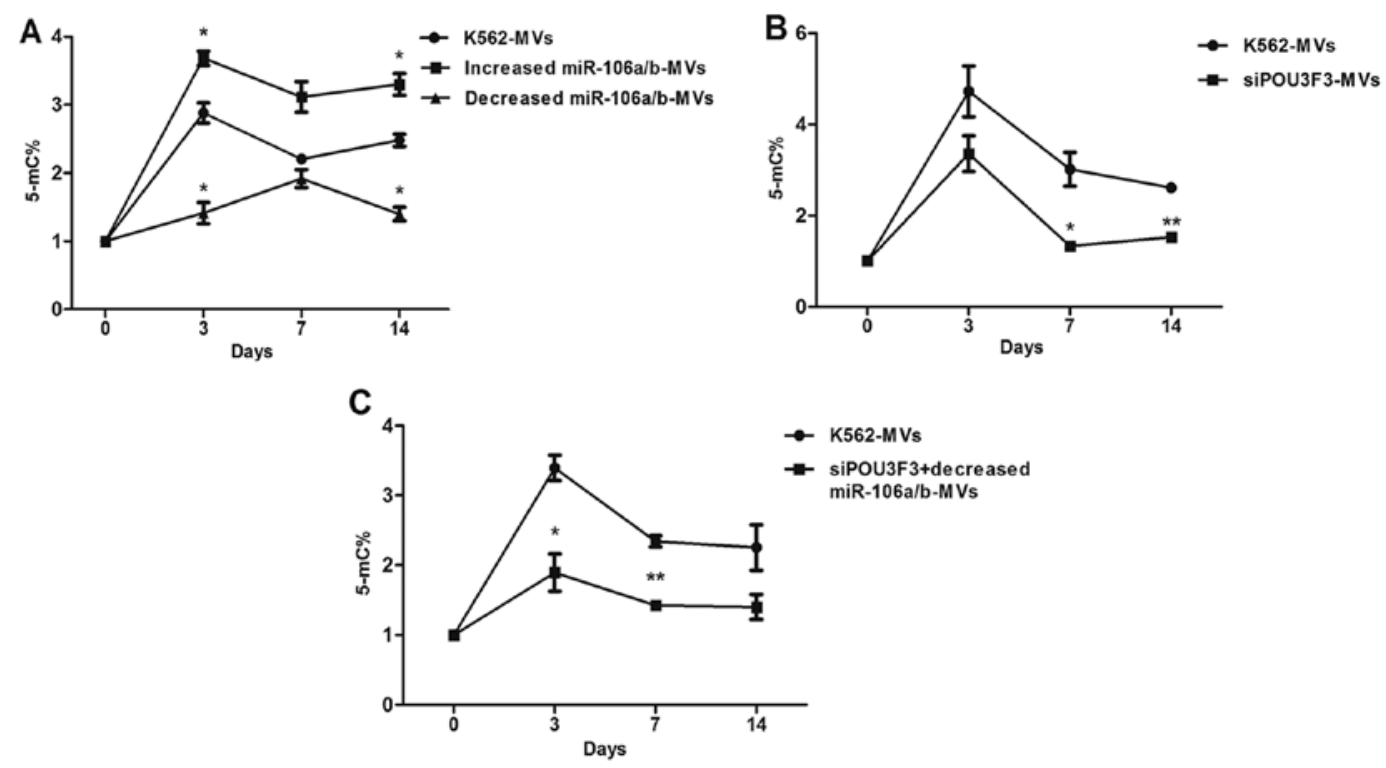

Figure 2. GDM is involved in transformation. GDM of recipient cells was performed with a DNA quantification kit. The data represent the mean values from 3 independent DNA preparations and the error bars the SEM. (A) Global DNA methylation of recipient cells induced by K562-MVs with increased/decreased miR-106a/b. (B) GDM of recipient cells induced by K562-MVs transfected with siPOU3F3. (C) GDM of recipient cells induced by K562-MVs co-transfected with inhibitors and siPOU3F3; ${ }^{*} \mathrm{P}<0.05$ and ${ }^{* *} \mathrm{P}<0.01$ when comparing the treatment group to the control. GDM, global DNA methylation; MVs, microvesicles.
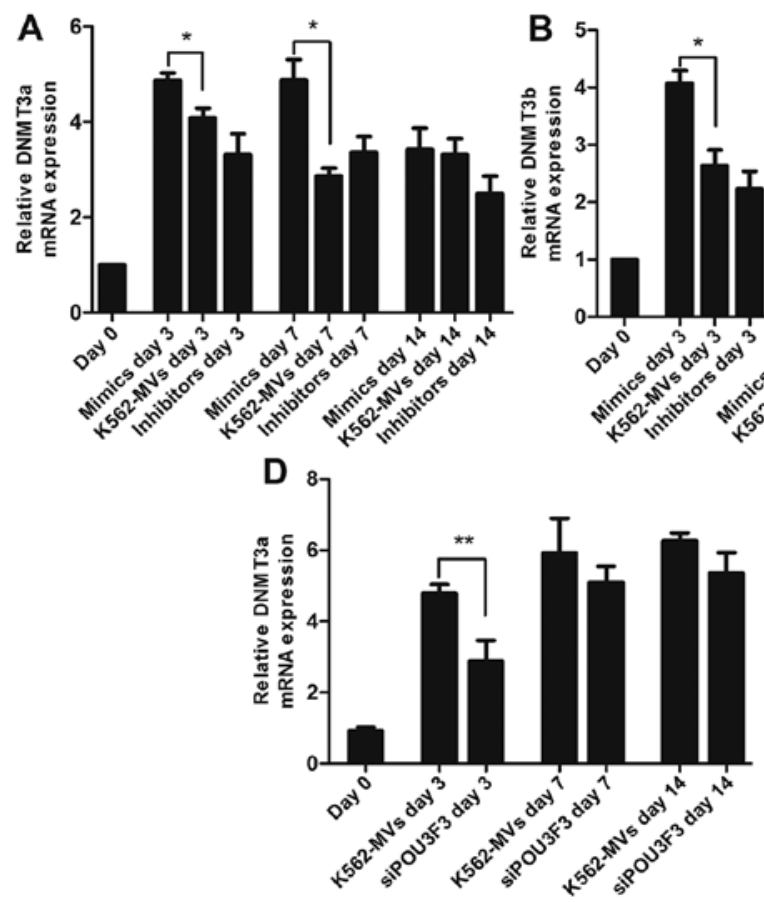
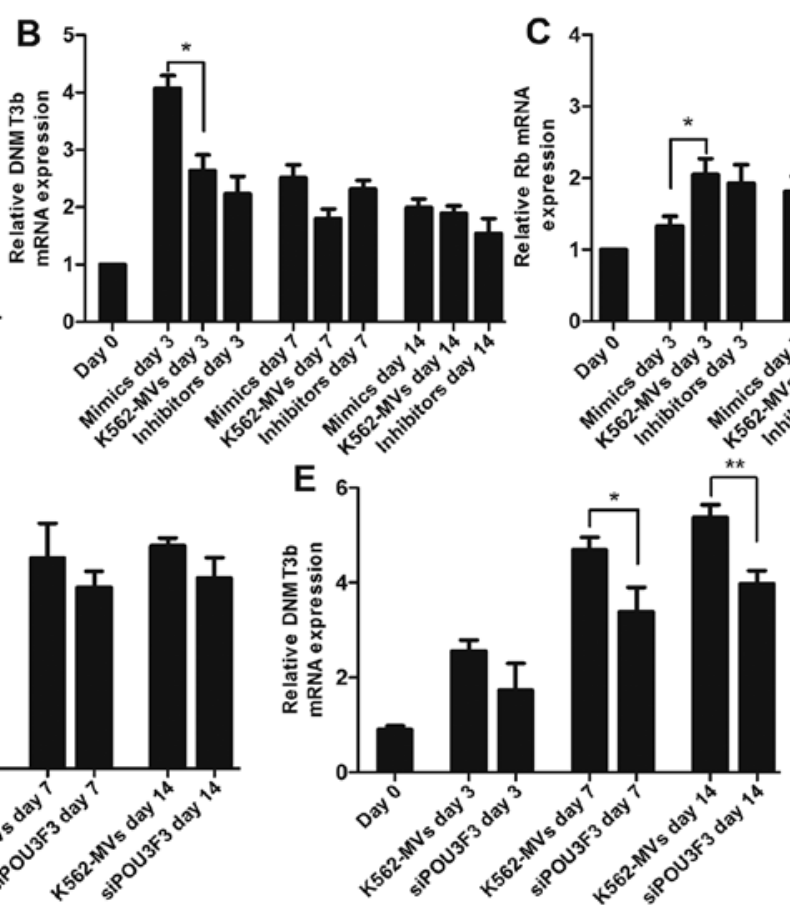

Figure 3. The mRNA level of methylation-related genes in recipient cells. (A-C) qRT-PCR was applied to determine the mRNA level of DNMT3a, DNMT3b and $\mathrm{Rb}$ with increased/decreased miR-106a/b expression at different time-points. ( $\mathrm{D}$ and $\mathrm{E}$ ) The mRNA level of DNMT3a and DNMT3b in recipient cells at different time-points treated with K562-MVs, which regulated the expression lincPOU3F3. The mean and SEM of at least 3 experiments performed in triplicate are shown; ${ }^{*} \mathrm{P}<0.05$ and ${ }^{* *} \mathrm{P}<0.01$. MVs; microvesicles.

the K562-MVs, the K562-MVs with siPOU3F3 decreased the GDM at days 7 and $14(\mathrm{P}<0.05)$, although it made no difference at the peak time (day 3; P $>0.05$; Fig. 2B). To analyze whether there is a synergistic effect between inhibitors and siPOU3F3, we also detected the GDM of recipient cells treated with K562-MVs co-transfected with inhibitors and siPOU3F3. Compared with the control, the treatment group was significantly decreased at day $3(\mathrm{P}<0.05)$ and day $7(\mathrm{P}<0.01)$, while the difference at day 14 was not significant ( $\mathrm{P}>0.05$; Fig. 2C).

Mechanisms of global DNA methylation change induced by $R N A$ within K562-MVs. We next investigated the changes in the levels of DNMTs by assessing the mRNA and protein levels of DNMT3a and DNMT3b. The mRNA and protein levels of DNMT3a and DNMT3b were generally increased 


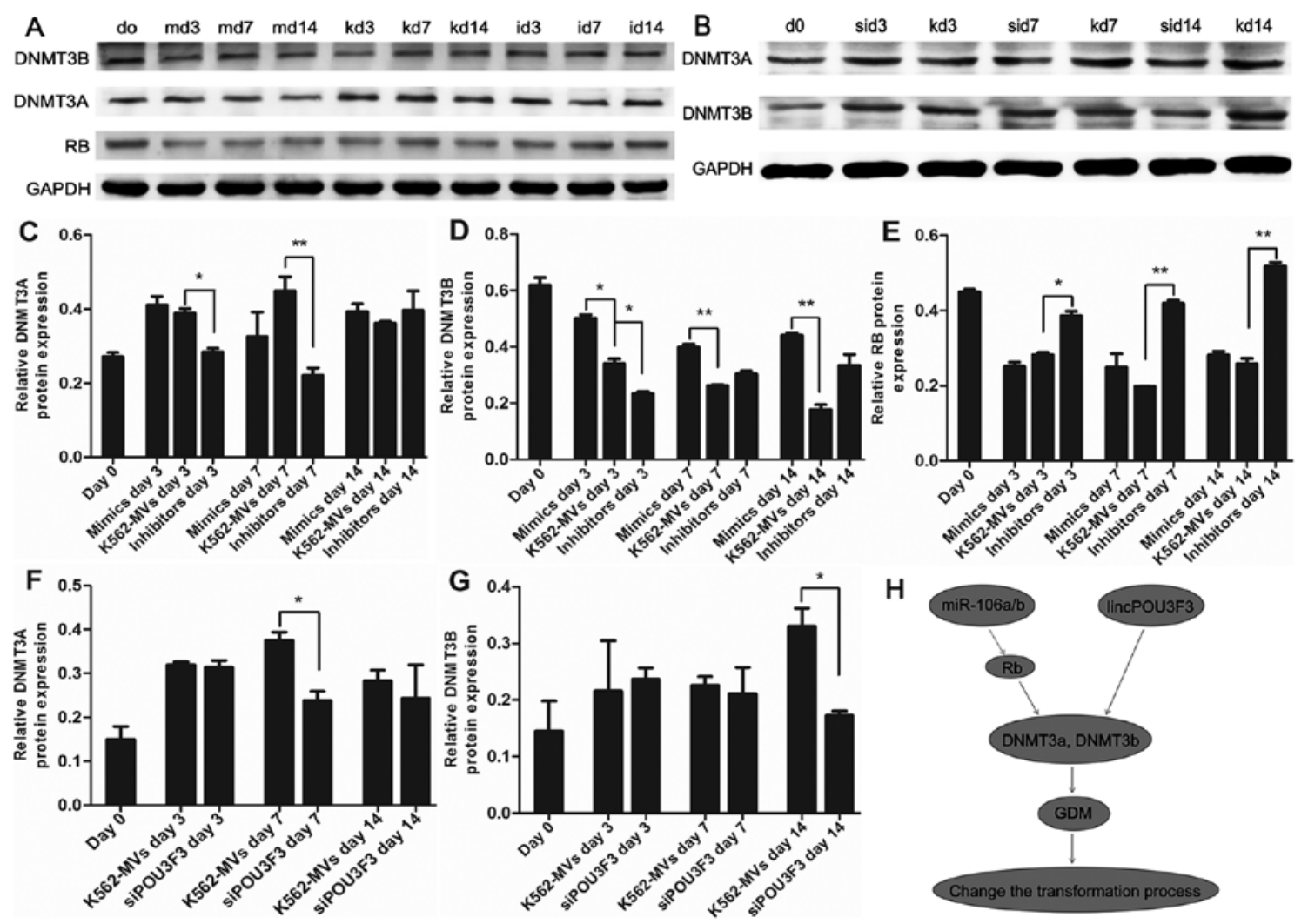

Figure 4. Epigenetic functions of miR-106a-5p, miR-106b-5p and lincPOU3F3 in the transformation. (A, C, D and E) The protein levels of DNMT3A, DNMT3B and RB in recipient cells induced by K562-MVs with regulated miR-106a/b at different time-points. GAPDH was used as a loading control. (B, F and G) The protein expression of DNMT3A and DNMT3B in recipient cells treated with siPOU3F3/k562-MVs were assessed by western blotting, GAPDH was used as a loading control. $(\mathrm{H})$ Proposed signaling pathways underlying the epigenetic effects of miR-106a-5p, miR-106b-5p and lincPOU3F3 in the transformation process; "P $<0.05$ and ${ }^{* *} \mathrm{P}<0.01$. m, mimics; k, K562-MVs; i, inhibitors; si, siPOU3F3. MVs, microvesicles.

during transformation induced by K562-MVs. The mRNA of DNMT3a was consistently increased on days 3 and 7 in the increased miR-106a/b group compared with the K562-MV group; in contrast, the protein expression in DNMT3a in the group with decreased miR-106a/b was suppressed (Figs. 3A, and $4 \mathrm{~A}$ and $\mathrm{C}$ ). miR-106a/b also increased the expression of DNMT3b mRNA and protein (Figs. 3B, and Fig. 4A and D). Mature miRNAs lead to translational suppression or mRNA degradation of the target protein-coding genes (14). According to the aforementioned data, miRNA may indirectly regulate the expression of DNMTs. Tang et al (15) found that RB suppressed DNMT3A promoter activity and mRNA/protein expression in lung cancer; in contrast, we determined that RB was the target of miR-106a/b using bioinformatics analyses (http://mirdb.org/miRDB/). Therefore, we detected the expression of RB in recipient cells. Increased/decreased miR-106a/b in K562-MVs led to a significant decrease/increase of Rb mRNA and protein observed on days 3,7 and $14(\mathrm{P}<0.05$ or $\mathrm{P}<0.01$; Figs. 3C and 4A and E). K562-MVs with siPOU3F3 significantly decreased the expression of the mRNA of DNMT3a at day 3 and protein at day 7 (Figs. 3D and 4B and F). In terms of DNMT3b, its mRNA and protein were both lowest at day 14 $(\mathrm{P}<0.05$ or $\mathrm{P}<0.01$, Figs. $3 \mathrm{E}$ and $4 \mathrm{~B}$ and $\mathrm{G})$. The mismatch between the mRNA and protein may be explained by the fact that MVs are packages of bioactive molecules that contain not only contributing factors but also detractors. Collectively, we proposed a new signaling pathway underlying the epigenetic effects of RNA in the transformation process. The increased

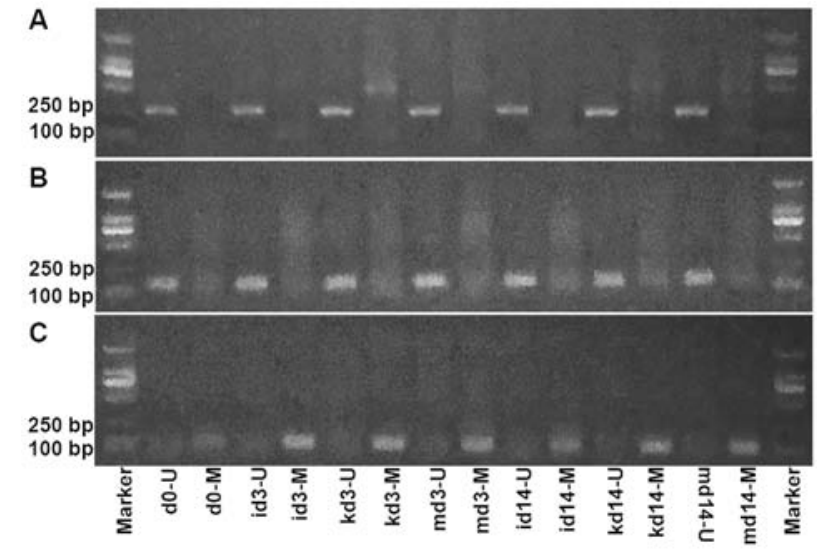

Figure 5. The promoter methylation of p53, c-Myc and DLX4. MSP analyses were carried out on the promoter regions of p53, c-Myc and DLX4 of recipient cells at day 0,3 and 14, respectively. Each sample was amplified by methylated primers and unmethylated primers. The presence of a visible PCR product in lane $U$ indicated the presence of unmethylated genes, the presence of a product in lane $\mathrm{M}$ indicated the presence of methylated genes. (A) MSP of the p53 promoter region in recipient cells. (B) MSP of the c-Myc promoter region in recipient cells. (C) MSP of the DLX4 promoter region in recipient cells. i, inhibitors; $\mathrm{k}, \mathrm{k} 562$; $\mathrm{m}$, mimics; $\mathrm{U}$, unmethylated; M, methylated. MSP, methylation-specific PCR.

expression of DNMT3a and DNMT3b induced by lincPOU3F3 may facilitate malignant transformation; whereas miR-106a/b may indirectly regulate DNMT3a and DNMT3b through $\mathrm{Rb}$, further affecting the transformation process (Fig. 4H). 
The promoter methylation of $p 53, c-M y c$ and DLX4. MSP analyses were carried out on the promoter regions of recipient cells of p53, c-Myc and DLX4 genes at day 0, 3 and 14, respectively. Each sample was amplified by methylated primers (M) and unmethylated primers (U). The promoters we analyzed of the p53 and c-Myc genes were both hypomethylated in the transformation process (day 3 and 14; Fig. 5A and B), whereas, the promoter of the DLX4 gene was hypermethylated compared with normal peripheral blood mobilization (day 0; Fig. 5C), which was in line with previous research which revealed that DLX4 hypermethylation was associated with disease progression in CML (8).

\section{Discussion}

Emission of MVs represents an important emerging element in the complexity of the cellular secretome, and likely acts in concert with the release of ions, metabolites, hormones, growth factors, cytokines and extracellular matrix molecules, with which vesiculation and cell-to-cell contact likely form a functional continuum (16). MVs released by tumor cells are detectable in patients with cancer and their number in the circulation correlates with poor prognosis (17). Our previous study demonstrated that BCR-ABL1-positive MVs initiated malignant transformation of normal hematopoietic transplants, providing implications for CML blast crisis (BC) and donor cell leukemia (DCL) (3). In the present study, we confirmed that miRNA and lincRNA within the MVs could lead to an altered level of GDM of the recipient cells. Although demethylation therapy has been applied in CML in some centers, little is known concerning the impact of DNA methylation on the evolution/progression of CML (18). The findings of the present study helped to further our understanding of the epigenetic change during the process of transformation, particularly DNA methylation. Further study should focus on the epigenetic modification induced by MVs and the potential to translate this knowledge into innovative approaches for monitoring and personalized therapy.

We further identified the connection between GDM and carcinogenesis. It has been reported for years that DNA-level epigenetic regulation plays a causative role in cancer and can thus be targeted for treatment of the disorder (19). In CML, Heller et al observed downregulated expression of many of these genes in BC-CML compared with CP-CML samples, using RNA-sequencing (20). However, a single DNA methylation change may act as a precipitating event in CML progression (21) and may provide a useful basis for revealing new targets of therapy in advanced CML. The present study shed much-needed light on an unconventional and poorly understood mechanism of exogenous RNA and its impact on GDM. GDM contributed to carcinogenesis via epigenetic silencing of well-known tumor-suppressor genes (TSGs) or regulators of cell proliferation $(22,23)$. In the present study, DLX4, a gene correlated with disease progression of CML (8), was hypermethylated during the process, which may be a pivotal regulator of the transformation.

One aspect merits further consideration involves the reason why miRNA and lincRNA in MVs induced global methylation of recipient cells. The complexity of extracellular vesicle-associated bioactive macromolecules supports a critical role in the modification of recipient cells (24). MVs can transfer specific proteins to target cells for the delivery of signaling pathways $(25,26)$. RNA represents the main compound of cancer-derived MVs $(27,28)$. In cancer, miRNAs and lincRNA may act either as potent oncogenes or TSGs and their deregulation has been associated with the etiology, progression and prognosis (29). Using bioinformatics analyses, we determined that lincPOU3F3 altered the expression of DNMTs. However, Tang et al (15) revealed that RB suppressed DNMT3A promoter activity and $\mathrm{mRNA} /$ protein expression in lung cancer, leading to the decrease of methylation level globally and TSGs specifically. RB is the target of miR-106a/b. As a result, we confirmed that miR-106a/b and lincPOU3F3 were involved in the transcriptional regulation of DNMT genes in our transformation model, which may induce global DNA methylation of the recipient cells. Thus, it could be speculated that miRNAs and lincRNAs in MVs provided important insight into leukemogenesis and development of CML.

Regulation of miR-106a/b and lincRNA in MVs could alter the endpoint of the transformation. We surmised that compounds in MVs could be regulated by two distinct pathways: via consequent overexpression of the content, such as miRNA mimics or inhibitors, in the parental cells; and via direct transfection of the content with MVs (30). Transfection into the parental cells was preferred since it could mimic the released thus far physiological process. Notably, we found that the expression of miRNA in K562-MVs and K562 after transfection with parental cells was inconsistent, indicating that MVs were shed following the selective incorporation of a host of molecular cargo, but not randomly released. The mechanism of how the MV content was loaded remained unclear. Several publications considered that the RNA-induced silencing complex (RISC), particularly the Ago2 protein, participated in the RNA transport from plasma into MVs $(31,32)$. It could be speculated that modification of Ago2 and RISC could help to regulate designated compound in MVs.

In summary, we found that horizontal transmission of miRNA and lincRNA triggered the epigenetic modification and downstream effect of target cells. Determinants of the cancer cell phenotype hardwired in driver factors are superimposed with more exogenous regulators, such as MVs, dictated by the epigenetic and differentiation programmers. This creates several levels of functional heterogeneity and interactive potential relevance of therapy.

\section{Acknowledgements}

The present study was supported by grants from the National Natural Science Foundation of China (NSFC) (nos. 81470333, 81470348 and 81500136).

\section{References}

1. Raposo G and Stoorvogel W: Extracellular vesicles: Exosomes, microvesicles, and friends. J Cell Biol 200: 373-383, 2013.

2. Boysen J, Nelson M, Magzoub G, Maiti GP, Sinha S, Goswami M, Vesely SK, Shanafelt TD, Kay NE and Ghosh AK: Dynamics of microvesicle generation in B-cell chronic lymphocytic leukemia: Implication in disease progression. Leukemia 31: 350-360, 2017.

3. Zhu X, You Y, Li Q, Zeng C, Fu F, Guo A, Zhang H, Zou P, Zhong Z, Wang H, et al: BCR-ABL1-positive microvesicles transform normal hematopoietic transplants through genomic instability: Implications for donor cell leukemia. Leukemia 28: 1666-1675, 2014. 
4. Ntziachristos P, Abdel-Wahab $\mathrm{O}$ and Aifantis I: Emerging concepts of epigenetic dysregulation in hematological malignancies. Nat Immunol 17: 1016-1024, 2016.

5. Wang LQ and Chim CS: DNA methylation of tumor-suppressor miRNA genes in chronic lymphocytic leukemia. Epigenomics 7: 461-473, 2015

6. San Jose-Eneriz E, Agirre X, Rodríguez-Otero P and Prosper F: Epigenetic regulation of cell signaling pathways in acute lymphoblastic leukemia. Epigenomics 5: 525-538, 2013.

7. Fong CY, Morison J and Dawson MA: Epigenetics in the hematologic malignancies. Haematologica 99: 1772-1783, 2014.

8. Zhou JD, Wang YX, Zhang TJ, Yang DQ, Yao DM, Guo H, Yang L, Ma JC, Wen XM, Yang J, et al: Epigenetic inactivation of $D L X 4$ is associated with disease progression in chronic myeloid leukemia. Biochem Biophys Res Commun 463: 1250-1256, 2015.

9. Esposito N, Colavita I, Quintarelli C, Sica AR, Peluso AL, Luciano L, Picardi M, Del Vecchio L, Buonomo T, Hughes TP, et al: SHP-1 expression accounts for resistance to imatinib treatment in Philadelphia chromosome-positive cells derived from patients with chronic myeloid leukemia. Blood 118: 3634-3644, 2011.

10. Elias MH, Baba AA, Husin A, Sulong S, Hassan R, Sim GA, Abdul Wahid SF and Ankathil R: HOXA4 gene promoter hypermethylation as an epigenetic mechanism mediating resistance to imatinib mesylate in chronic myeloid leukemia patients. Biomed Res Int 2013: 129715, 2013.

11. Chmelarova M, Kos S, Dvorakova E, Spacek J, Laco J, Ruszova E, Hrochova $\mathrm{K}$ and Palicka V: Importance of promoter methylation of GATA4 and TP53 genes in endometrioid carcinoma of endometrium. Clin Chem Lab Med 52: 1229-1234, 2014.

12. de Souza CR, Leal MF, Calcagno DQ, Costa Sozinho EK, Borges BN, Montenegro RC, Dos Santos AK, Dos Santos SE, Ribeiro HF, Assumpção PP, et al: MYC deregulation in gastric cancer and its clinicopathological implications. PLoS One 8: e64420, 2013.

13. Zhang TJ, Zhou JD, Yang DQ, Wang YX, Yao DM, Ma JC, Wen XM, Guo H, Lin J and Qian J: Hypermethylation of $D L X 4$ predicts poor clinical outcome in patients with myelodysplastic syndrome. Clin Chem Lab Med 54: 865-871, 2016.

14. Rupaimoole R, Calin GA, Lopez-Berestein G and Sood AK: miRNA deregulation in cancer cells and the tumor microenvironment. Cancer Discov 6: 235-246, 2016.

15. Tang YA, Lin RK, Tsai YT, Hsu HS, Yang YC, Chen CY and Wang YC: MDM2 overexpression deregulates the transcriptional control of $\mathrm{RB} / \mathrm{E} 2 \mathrm{~F}$ leading to DNA methyltransferase 3A overexpression in lung cancer. Clin Cancer Res 18: 4325-4333, 2012.

16. Taylor DD and Gercel-Taylor C: The origin, function, and diagnostic potential of RNA within extracellular vesicles present in human biological fluids. Front Genet 4: 142, 2013.

17. Setti M, Osti D, Richichi C, Ortensi B, Del Bene M, Fornasari L, Beznoussenko G, Mironov A, Rappa G, Cuomo A, et al: Extracellular vesicle-mediated transfer of CLIC1 protein is a novel mechanism for the regulation of glioblastoma growth. Oncotarget 6: 31413-31427, 2015.

18. Jin Y, Zhou J, Xu F, Jin B, Cui L, Wang Y, Du X, Li J, Li P, Ren R, et al: Targeting methyltransferase PRMT5 eliminates leukemia stem cells in chronic myelogenous leukemia. J Clin Invest 126: 3961-3980, 2016.
19. Lissa D and Robles AI: Methylation analyses in liquid biopsy. Transl Lung Cancer Res 5: 492-504, 2016.

20. Heller G, Topakian T, Altenberger C, Cerny-Reiterer S, Herndlhofer S, Ziegler B, Datlinger P, Byrgazov K, Bock C, Mannhalter C, et al: Next-generation sequencing identifies major DNA methylation changes during progression of $\mathrm{Ph}^{+}$chronic myeloid leukemia. Leukemia 30: 1861-1868, 2016.

21. Amabile G, Di Ruscio A, Müller F, Welner RS, Yang H, Ebralidze AK, Zhang H, Levantini E, Qi L, Martinelli G, et al: Dissecting the role of aberrant DNA methylation in human leukaemia. Nat Commun 6: 7091, 2015.

22. Han F, Liu W, Jiang X, Shi X, Yin L, Ao L, Cui Z, Li Y, Huang C, Cao J, et al: SOX30, a novel epigenetic silenced tumor suppressor, promotes tumor cell apoptosis by transcriptional activating p53 in lung cancer. Oncogene 34: 4391-4402, 2015.

23. Kikuyama M, Takeshima H, Kinoshita T, Okochi-Takada E, Wakabayashi M, Akashi-Tanaka S, Ogawa T, Seto Y and Ushijima T: Development of a novel approach, the epigenome-based outlier approach, to identify tumor-suppressor genes silenced by aberrant DNA methylation. Cancer Lett 322: 204-212, 2012.

24. Li L, Tang J, Zhang B, Yang W, LiuGao M, Wang R, Tan Y, Fan J, Chang Y, Fu J, et al: Epigenetic modification of MiR-429 promotes liver tumour-initiating cell properties by targeting $\mathrm{Rb}$ binding protein 4 . Gut 64: 156-167, 2015.

25. Camussi G, Deregibus MC, Bruno S, Grange C, Fonsato V and Tetta C: Exosome/microvesicle-mediated epigenetic reprogramming of cells. Am J Cancer Res 1: 98-110, 2011.

26. Antonyak MA and Cerione RA: Microvesicles as mediators of intercellular communication in cancer. Methods Mol Biol 1165: 147-173, 2014.

27. Ratajczak MZ, Ratajczak D and Pedziwiatr D: Extracellular microvesicles (ExMVs) in cell to cell communication: A role of telocytes. Adv Exp Med Biol 913: 41-49, 2016.

28. ElSharawy A, Röder C, Becker T, Habermann JK, Schreiber S, Rosenstiel $\mathrm{P}$ and Kalthoff $\mathrm{H}$ : Concentration of circulating miRNA-containing particles in serum enhances miRNA detection and reflects CRC tissue-related deregulations. Oncotarget 7: 75353-75365, 2016

29. Espinosa-Parrilla Y, Muñoz X, Bonet C, Garcia N, Venceslá A, Yiannakouris N, Naccarati A, Sieri S, Panico S, Huerta JM, et al: Genetic association of gastric cancer with miRNA clusters including the cancer-related genes MIR29, MIR25, MIR93 and MIR106: Results from the EPIC-EURGAST study. Int J Cancer 135: 2065-2076, 2014.

30. Zhang HM, Li Q, Zhu X, Liu W, Hu H, Liu T, Cheng F, You Y, Zhong Z, Zou P, et al: miR-146b-5p within BCR-ABL1-positive microvesicles promotes leukemic transformation of hematopoietic cells. Cancer Res 76: 2901-2911, 2016.

31. Lv Z, Wei Y, Wang D, Zhang CY, Zen K and Li L: Argonaute 2 in cell-secreted microvesicles guides the function of secreted miRNAs in recipient cells. PLoS One 9: e103599, 2014.

32. Turchinovich A, Weiz L and Burwinkel B: Isolation of circulating microRNA associated with RNA-binding protein. Methods Mol Biol 1024: 97-107, 2013. 